\title{
Development and Validation of RP-HPLC Method for
} Simultaneous Estimation of Moexipril and

\section{Hydrochlorothiazide in Bulk and Tablet Dosage Form}

\author{
Rao $\mathrm{AL}^{1 *}$, Prasanthi $\mathrm{T}^{2}$ and Latha $\mathrm{PM}^{3}$ \\ 1Professor \& Principal, Department of Pharmaceutical Analysis, VV Institute of \\ Pharmaceutical Sciences, India \\ ${ }^{2}$ Associate Professor, Department of Pharmaceutical Analysis, VV Institute of \\ Pharmaceutical Sciences, India
}

\section{Research Article \\ Volume 1 Issue 7}

Received Date: November 07, 2017

Published Date: November 15, 2017

${ }^{3}$ Student, Department of Pharmaceutical Analysis, VV Institute of Pharmaceutical Sciences, India

*Corresponding author: Lakshmana Rao A, Professor and Principal, VV Institute of Pharmaceutical Sciences, Gudlavalleru, Andhra Pradesh, India, E-mail: dralrao@gmail.com

\section{Abstract}

A simple, fast, precise reverse phase and isocratic HPLC method was developed for the separation and quantification of Moexipril (MXP) and Hydrochlorothiazide (HCT) in pharmaceutical dosage form. The quantification was carried out using Kromasil C18 (250 x $4.6 \mathrm{~mm}, 5 \mu \mathrm{m}$ ) enhanced polar selectivity column and mobile phase comprised of orthophosphoric acid buffer and acetonitrile in proportion of ratio $70: 30 \mathrm{v} / \mathrm{v}$ and degassed under ultra sonication. The flow rate was $1.0 \mathrm{~mL} / \mathrm{min}$ and the effluent was monitored at $230 \mathrm{~nm}$. The retention time of Moexipril and Hydrochlorothiazide were 2.4 and 3.2min respectively. The method was validated in terms of linearity, precision, accuracy, specificity, limit of detection and limit of quantitation. Linearity of Moexipril and Hydrochlorothiazide were in the range of 37.5 to $225 \mu \mathrm{g} / \mathrm{mL}$ and 62.5 to $375 \mu \mathrm{g} / \mathrm{mL}$ respectively. The percentage recoveries of both the drugs were $98.44 \%$ and $98.80 \%$ for Moexipril and Hydrochlorothiazide respectively from the tablet formulation. The proposed method is suitable for simultaneous determination of Moexipril and Hydrochlorothiazide in pharmaceutical dosage form.

Keywords: Moexipril; Hydrochlorothiazide; RP-HPLC; Validation

Abbreviations: ACE: Angiotensin Converting Enzyme; LOD: Limit of Detection; LOQ: Limit of Quantification; OPA: Ortho Phosphoric Acid; HCT: Hydrochlorothiazide; MXP: Moexipril

\section{Introduction}

Moexipril [1] is chemically (3S)-2-[(2S)-2-\{[(2S)-1ethoxy-1-oxo-4-phenylbutan-2-yl] amino\} propanoyl]- 6,7-dimethoxy-1,2,3,4-tetrahydroisoquinoline-3-

carboxylic acid (Figure 1). It is a non-sulfhydryl containing precursor of the active angiotensin-converting enzyme (ACE) inhibitor moexiprilat. It is used to treat high blood pressure (hypertension). The mechanism through which Moexiprilat lowers blood pressure is believed to be primarily inhibition of Angiotensin Converting Enzyme (ACE) activity. Although the principal mechanism of Moexipril in blood pressure reduction is 


\section{Open Access Journal of Pharmaceutical Research}

believed to be through the renin-angiotensin-aldosterone system, ACE inhibitors have some effect on blood pressure even in apparent low-renin hypertension.

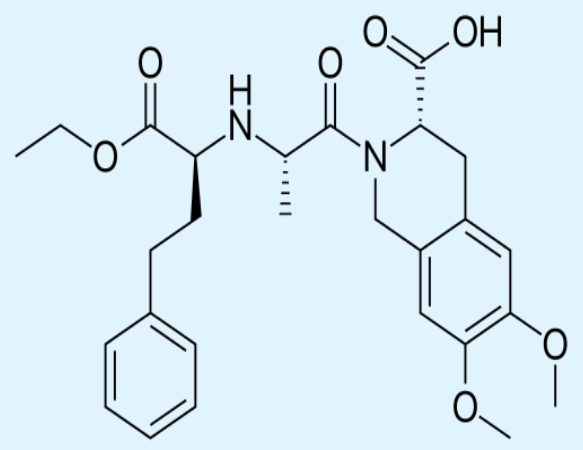

Figure 1: Structure of Moexipril.

Hydrochlorothiazide (HCT) [2,3] is chemically described as 6-chloro-3,4-dihydro- $2 \mathrm{H}-1,2,4-$ benzothiadiazine-7-sulfonamide 1,1-dioxide (Figure 2). Hydrochlorothiazide is a thiazide diuretic, inhibits water reabsorption in the nephron by inhibiting the sodiumchloride symporter (SLC12A3) in the distal convoluted tubule. It reduces the reabsorption of electrolytes from the renal tubules. This results in increased excretion of water and electrolytes, including sodium, potassium, chloride, and magnesium. The combination of MXP and HCT is available as tablet dosage form.

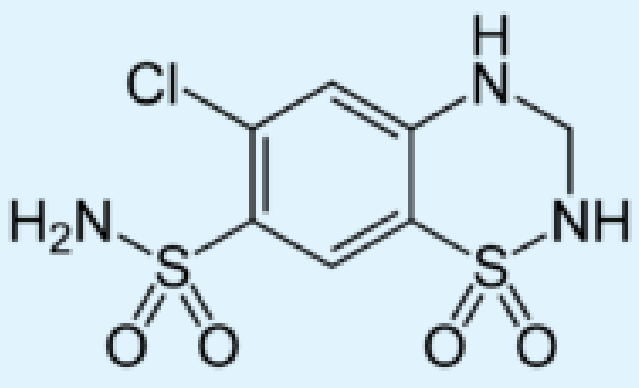

Figure 2: Structure of Hydrochlorothiazide.

Several analytical methods have been reported for the determination of MXP and HCT alone in biological fluids and in pharmaceutical formulations. Literature survey revealed several analytical methods have been reported for individual estimation [4-7] of MXP and HCT and in combination with other drugs [8-12] but only two HPLC methods [13,14] were reported for simultaneous estimation of MXP and HCT. Hence an attempt has been made to develop a simple, precise, reliable, sensitive and selective HPLC method for the analysis of MXP and HCT in bulk samples and in combined tablet dosage form. The proposed method was validated according to ICH guidelines [15].

\section{Materials and Methods}

\section{Materials}

Moexipril and Hydrochlorothiazide were obtained as gift samples from Spectrum Labs, Hyderabad. Moexipril and Hydrochlorothiazide combined dosage form tablets were purchased from local market. HPLC grade acetonitrile, methanol and analytical grade, orthophosphoric acid was obtained from Merck Chemicals Ltd, Mumbai. Milli-Q water was used throughout the experiment dispensed through $0.22 \mu$ filter of the Milli-Q water purification system from Merck Millipore.

\section{Chromatographic Conditions}

Waters Alliance HPLC, integrated with Auto Sampler and UV detector was used. The output of signal was monitored and integrated using waters Empower 2 software. Kromasil C18, 250 x $4.6 \mathrm{~mm}, 5 \mu \mathrm{m}$ particle size enhanced polar selectivity column was used as stationary phase. Mobile phase was comprised of $0.1 \%$ ortho phosphoric acid and acetonitrile in proportion of ratio 70:30v/v. The mobile phase was mixed, filtered through $0.45 \mu$ membrane filter and degassed under ultrasonication. Water: acetonitrile $(50: 50 \mathrm{v} / \mathrm{v})$ was used as diluent. Injection volume was $10 \mu \mathrm{L}$ and flow rate was $1 \mathrm{~mL} / \mathrm{min}$ and run time was $7 \mathrm{~min}$. The column was maintained at ambient temperature and the eluent was monitored at $230 \mathrm{~nm}$.

\section{Preparation of Standard Solution}

Standard stock solutions of Moexipril and Hydrochlorothiazide $(\mu \mathrm{g} / \mathrm{mL})$ were prepared by dissolving $15 \mathrm{mg}$ of Moexipril and $25 \mathrm{mg}$ of Hydrochlorothiazide dissolved in sufficient mobile phase. After that filtered the solution using $0.45 \mathrm{micron}$ syringe filter and sonicated for $5 \mathrm{~min}$ and dilute to $100 \mathrm{~mL}$ with mobile phase. Further dilutions made by adding $1 \mathrm{~mL}$ of stock solution to $10 \mathrm{~mL}$ of mobile phase. Standard stock solution was diluted in mobile phase to contain a mixture of Moexipril and Hydrochlorothiazide in over the linearity range from 37.5 to $220 \mu \mathrm{g} / \mathrm{mL}$ and 62.5 to $375 \mu \mathrm{g} / \mathrm{mL}$ respectively.

\section{Preparation of Sample Solution}

20 tablets (each tablet contains 15mg of Moexipril and 25mg of Hydrochlorothiazide) were weighed and taken 


\section{Open Access Journal of Pharmaceutical Research}

into a mortar and crushed to fine powder and uniformly mixed. Tablet stock solutions of Moexipril and Hydrochlorothiazide $(\mu \mathrm{g} / \mathrm{mL})$ were prepared by dissolving weight equivalent to $15 \mathrm{mg}$ of Moexipril and 25mg of Hydrochlorothiazide and dissolved in sufficient mobile phase. After that filtered the solution using $0.45 \mu$ syringe filter and Sonicated for $5 \mathrm{~min}$ and dilute to $100 \mathrm{~mL}$ with mobile phase. Further dilutions are made by adding $1 \mathrm{~mL}$ of stock solution to $10 \mathrm{~mL}$ of mobile phase. $10 \mu \mathrm{L}$ of the sample solution was injected in to the HPLC system.

\section{Results and Discussion}

\section{Method Development}

To develop a simple and robust method for the simultaneous determination of MXP and HCT in combined tablet dosage form using HPLC. Solubility of standard drug was checked and based on solubility different mobile phase compositions were pumped in binary mode to achieve the resolution of drug peaks, initial experimental conditions were column with C18 stationery phase, water and acetonitrile as organic solvent at a flow rate of $1.0 \mathrm{~mL} / \mathrm{min}$ was chosen and respective injections shown considerable resolution of drug peaks with a run time of $10 \mathrm{~min}$. For better resolution the water was replaced by $0.1 \%$ ortho phosphoric acid (OPA) and finally a premixed composition $(70: 30, \mathrm{v} / \mathrm{v})$ of $0.1 \%$ OPA and acetonitrile was chosen as mobile phase, and the Kromasil stationary phase with enhanced polar selectivity of particle size $5 \mu \mathrm{m}, 250 \times 4.6 \mathrm{~mm}$ was used and the runtime of the method was got minimized to $7 \mathrm{~min}$ with better resolution, better peak shape was found with mobile phase as diluent in samples injected into chromatographic system. Injections with UV detection at a wavelength of $230 \mathrm{~nm}$ for both drug peaks in the trail results were observed to be specific, precise and fast.

\section{Validation of the Proposed Method}

System Suitability: System suitability test was performed on each day prior to initiation of the validation run. The system suitability results of the method are presented in (Tables $1 \& 2$ ).

\begin{tabular}{|c|c|c|c|c|}
\hline Injection & Retention time (min) & Peak area & Theoretical plates & Tailing factor \\
\hline 1 & 2.401 & 785185 & 4978 & 1.25 \\
\hline 2 & 2.402 & 781793 & 4595 & 1.23 \\
\hline 3 & 2.403 & 783322 & 4921 & 1.28 \\
\hline 4 & 2.403 & 782952 & 4844 & 1.28 \\
\hline 5 & 2.404 & 784703 & 4949 & 1.27 \\
\hline 6 & 2.404 & 786933 & 4864 & 1.28 \\
\hline Mean & - & 784148 & - & - \\
\hline SD & - & 1833.1 & - & - \\
\hline
\end{tabular}

Table 1: Results for system suitability of Moexipril.

\begin{tabular}{|c|c|c|c|c|}
\hline Injection & Retention time (min) & Peak area & Theoretical plates & Tailing factor \\
\hline 1 & 3.295 & 2173551 & 8535 & 1.17 \\
\hline 2 & 3.296 & 2181287 & 8502 & 1.13 \\
\hline 3 & 3.298 & 2178698 & 8515 & 1.15 \\
\hline 4 & 3.299 & 2181255 & 8406 & 1.15 \\
\hline 5 & 3.3 & 2188768 & 8598 & 1.16 \\
\hline 6 & 3.304 & 2174555 & 8653 & 1.17 \\
\hline Mean & & 2179685 & - & - \\
\hline SD & & 5521.9 & - & - \\
\hline RSD & & 0.3 & - & - \\
\hline
\end{tabular}

Table 2: Results for system suitability of Hydrochlorothiazide. 


\section{Open Access Journal of Pharmaceutical Research}

Specificity: A study was conducted to establish specificity of the proposed method involved injecting diluent and placebo using the chromatographic conditions defined for the proposed method. The blank chromatogram showed no interference peaks at the retention time of Moexipril and Hydrochlorothiazide respectively. This indicates that diluent solution used in sample preparation do not interfere in the estimation of Moexipril and Hydrochlorothiazide. Similarly the placebo sample chromatogram showed no interference peaks at the retention time of Moexipril and Hydrochlorothiazide respectively. Additional peaks were observed in the channel may be due to excipients present in the formulations. These peaks however did not interfere with the standard peak indicating that the placebo used in sample preparation do not interfere in estimation of Moexipril and Hydrochlorothiazide in combination tablet, which demonstrates the specificity of the proposed method. The chromatogram of the blank and placebo using the proposed method for Moexipril and Hydrochlorothiazide is shown in Figures 3 \& 4. The typical chromatogram of the sample using the proposed method for Moexipril and Hydrochlorothiazide is shown in Figure 5.

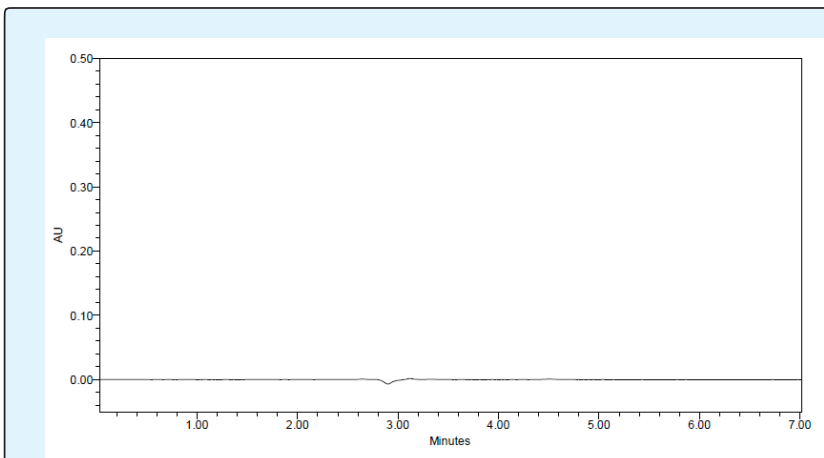

Figure 3: Blank Chromatogram.

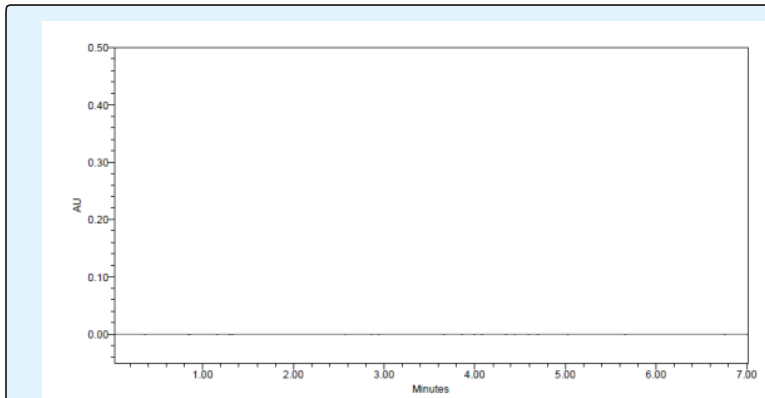

Figure 4: Placebo Chromatogram.

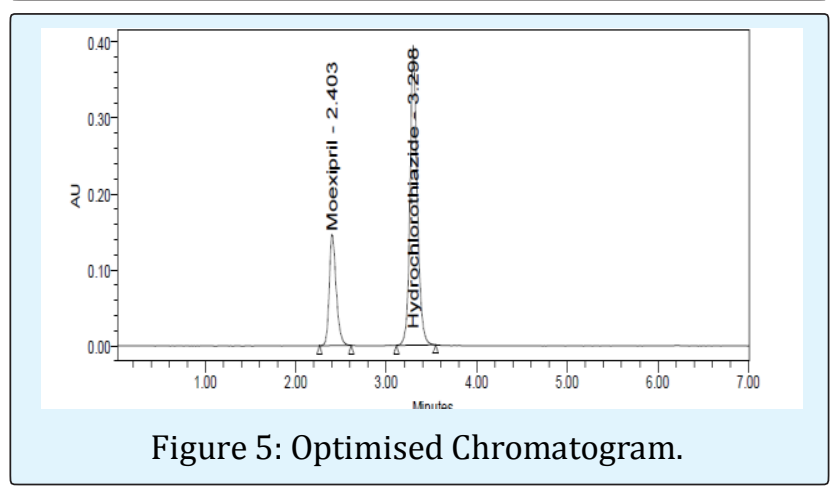

Linearity: Detector response for the proposed method determined to be linear over the range of five concentration levels prepared and injected, 37.5 to $220 \mu \mathrm{g} / \mathrm{mL}$ for Moexipril and 62.5 to $375 \mu \mathrm{g} / \mathrm{mL}$ for Hydrochlorothiazide. The calibration curve was plotted as concentration of the respective drug versus the obtained peak area at each concentration level. The linearity of the method was evaluated by linear regression analysis. The linear regression equation of proposed method representing slope and intercept for Moexipril and Hydrochlorothiazide were given in (Figures 6 \& 7). The statistical data calculated for Moexipril and Hydrochlorothiazide found to be accurate and was given in Table 3.

\begin{tabular}{|c|c|c|c|c|}
\hline \multirow{2}{*}{ S. No. } & \multicolumn{2}{|c|}{ MXP } & \multicolumn{2}{|c|}{ HCT } \\
\hline & Conc. $(\mu \mathrm{g} / \mathrm{mL})$ & Peak area & Conc. $(\mu \mathrm{g} / \mathrm{mL})$ & Peak area \\
\hline 1 & 0 & 0 & 0 & 0 \\
\hline 2 & 37.5 & 163560 & 62.5 & 466283 \\
\hline 3 & 75 & 324926 & 125 & 914065 \\
\hline 4 & 112.5 & 501268 & 187.5 & 1407465 \\
\hline 5 & 150 & 684763 & 250 & 1892699 \\
\hline 6 & 187.5 & 826162 & 312.5 & 2322923 \\
\hline 7 & 225 & 985168 & 375 & 2728770 \\
\hline Slope & \multicolumn{2}{|c|}{4419.6} & \multicolumn{2}{|c|}{7359} \\
\hline Intercept & \multicolumn{2}{|c|}{776.8} & \multicolumn{2}{|c|}{10505} \\
\hline Regression Equation(y) & \multicolumn{2}{|c|}{$y=4419.6 x+776.89$} & \multicolumn{2}{|c|}{$y=7359 x+10505$} \\
\hline Correlation Coefficient & \multicolumn{2}{|c|}{0.999} & \multicolumn{2}{|c|}{0.999} \\
\hline
\end{tabular}

Table 3: Linearity results. 


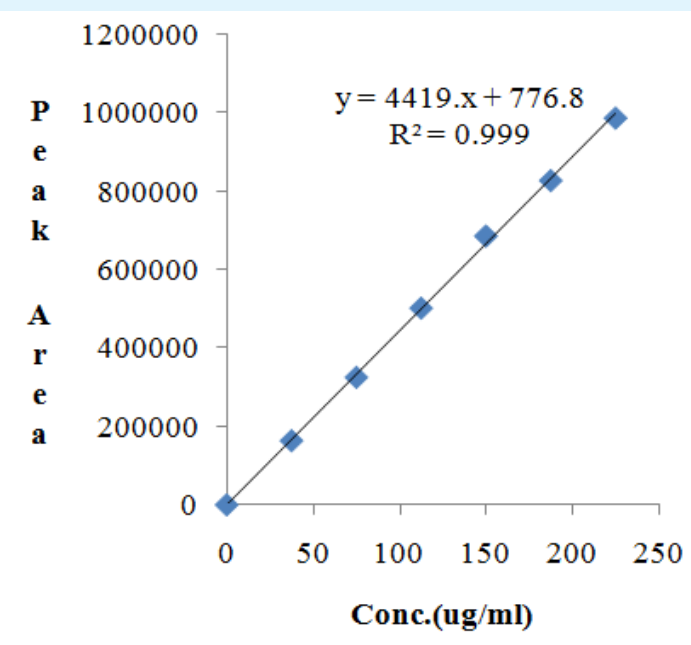

Figure 6: Linearity curve of MXP.

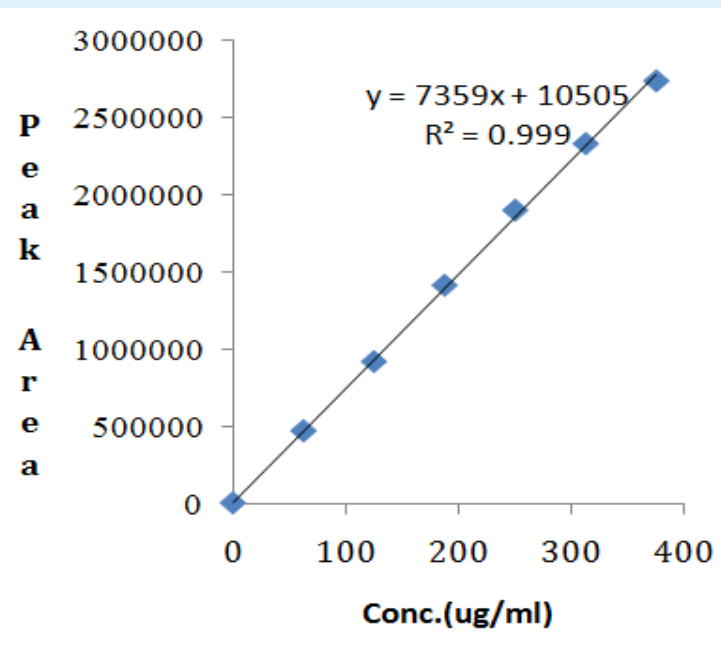

Figure 7: Linearity curve of HCT.
Accuracy: The accuracy of the method was determined on three concentration levels by recovery experiments. The recovery studies were carried out in triplicate preparations on blend collected from twenty tablets of Moexipril and Hydrochlorothiazide and analyzed as per the proposed method. The percentage recoveries found are in the range of 98.31 to 98.54 and 98.39 to 99.54 for Moexipril and Hydrochlorothiazide respectively. From the data obtained, the proposed method found to be accurate. The results are summarized in Tables $4 \& 5$.

\begin{tabular}{|c|c|c|c|c|c|c|}
\hline Recovery leve & $\begin{array}{c}\text { Amount taken } \\
(\mu \mathrm{g} / \mathrm{mL})\end{array}$ & Area & Average area & $\begin{array}{c}\text { Amount recovered } \\
(\mu \mathrm{g} / \mathrm{mL})\end{array}$ & $\begin{array}{c}\text { Recovery } \\
(\%)\end{array}$ & $\begin{array}{c}\text { Mean } \\
\text { Recovery }\end{array}$ \\
\hline \multirow{3}{*}{$50 \%$} & 75 & 989071 & \multirow{3}{*}{989440} & \multirow{3}{*}{73.73} & \multirow{3}{*}{98.31} & \multirow{9}{*}{98.44} \\
\hline & 75 & 989006 & & & & \\
\hline & 75 & 990245 & & & & \\
\hline \multirow{3}{*}{$100 \%$} & 150 & 1315379 & \multirow{3}{*}{1316779} & \multirow{3}{*}{147.81} & \multirow{3}{*}{98.54} & \\
\hline & 150 & 1318161 & & & & \\
\hline & 150 & 1316799 & & & & \\
\hline \multirow{3}{*}{$150 \%$} & 225 & 1614810 & \multirow{3}{*}{1632761} & \multirow{3}{*}{221.57} & \multirow{3}{*}{98.48} & \\
\hline & 225 & 1643207 & & & & \\
\hline & 225 & 1640266 & & & & \\
\hline
\end{tabular}

Table 4: Recovery results for Moexipril.

\begin{tabular}{|c|c|c|c|c|c|c|}
\hline $\begin{array}{c}\text { Recovery } \\
\text { level }\end{array}$ & $\begin{array}{l}\text { Amount taken } \\
(\mu \mathrm{g} / \mathrm{mL})\end{array}$ & Area & Average area & $\begin{array}{c}\text { Amount recovered } \\
(\mu \mathrm{g} / \mathrm{mL})\end{array}$ & Recovery (\%) & $\begin{array}{c}\text { Mean } \\
\text { Recovery }\end{array}$ \\
\hline \multirow{3}{*}{$50 \%$} & 125 & 2759120 & \multirow{3}{*}{2764976} & \multirow{3}{*}{124.3} & \multirow{3}{*}{99.44} & \multirow{9}{*}{98.8} \\
\hline & 125 & 2761114 & & & & \\
\hline & 125 & 2774695 & & & & \\
\hline \multirow{3}{*}{$100 \%$} & 250 & 3657620 & \multirow{3}{*}{3664070} & \multirow{3}{*}{246.48} & \multirow{3}{*}{98.59} & \\
\hline & 250 & 3662926 & & & & \\
\hline & 250 & 3671665 & & & & \\
\hline \multirow{3}{*}{$150 \%$} & 375 & 4555748 & \multirow{3}{*}{4565502} & \multirow{3}{*}{368.97} & \multirow{3}{*}{98.39} & \\
\hline & 375 & 4567343 & & & & \\
\hline & 375 & 4573414 & & & & \\
\hline
\end{tabular}

Table 5: Recovery results for Hydrochlorothiazide. 


\section{Open Access Journal of Pharmaceutical Research}

Precision: The method precision study for six sample preparations in marketed samples showed a RSD of $0.2 \%$ and $0.4 \%$, respectively for MXP and HCT. For the intermediate precision, a study carried out by the same analyst working on different day. The results calculated as inter-day RSD (For Standard) corresponded to $0.5 \%$ for both MXP and HCT respectively. Both results together with the individual results are showing that the proposed analytical technique has a good intermediate precision. Results are summarized in Table 6.

\begin{tabular}{|c|c|c|c|c|c|c|}
\hline \multirow{2}{*}{ S. No. } & \multicolumn{4}{|c|}{ Intra-day Precision } & \multicolumn{2}{c|}{ Inter-day Precision } \\
\cline { 2 - 6 } & \multicolumn{2}{|c|}{ MXP } & HCT & \multirow{2}{*}{ HCT } \\
\cline { 2 - 6 } & Rt (min) & Area & Rt (min) & Area & & 1728154 \\
\hline 1 & 2.404 & 784137 & 3.297 & 2185754 & 625342 & 1732848 \\
\hline 2 & 2.405 & 781418 & 3.297 & 2181804 & 630727 & 1741627 \\
\hline 3 & 2.406 & 782581 & 3.299 & 2170011 & 623411 & 1723147 \\
\hline 4 & 2.406 & 785162 & 3.3 & 2188986 & 626086 & 1747213 \\
\hline 5 & 2.407 & 781331 & 3.3 & 2193655 & 621878 & 1741166 \\
\hline 6 & 2.408 & 785639 & 3.3 & 2172442 & 627735 & 1735693 \\
\hline Mean & - & 783378 & - & 2182109 & 625863 & 9167.4 \\
\hline S.D & - & 1872.9 & - & 9314.4 & 3142.5 & 0.5 \\
\hline \%RSD & - & 0.2 & - & 0.4 & 0.5 & \\
\hline
\end{tabular}

Table 6: Precision results.

Detection and Quantification limit: The LOD is the lowest concentration of the analyte that can be detected and LOQ is the lowest concentration that can be quantified with acceptable precision and accuracy. The limit of detection (LOD) and limit of quantification (LOQ) for Moexipril were $0.04 \mu \mathrm{g} / \mathrm{mL}$ and $0.19 \mu \mathrm{g} / \mathrm{mL}$ respectively and for hydrochlorothiazide were $0.13 \mu \mathrm{g} / \mathrm{mL}$ and $0.59 \mu \mathrm{g} / \mathrm{mL}$ respectively by the proposed method.

Robustness: Small deliberate changes in method like flow rate, mobile phase ratio, and temperature are made but there were no recognized change in the result and are within range as per ICH Guide lines. The data was presented in Table 7.

\begin{tabular}{|c|c|c|c|}
\hline S. No. & Robustness condition & MXP \%RSD & HCT \%RSD \\
\hline 1 & Flow minus $(0.9 \mathrm{~mL} / \mathrm{min})$ & 1.1 & 0.6 \\
\hline 2 & Flow plus $(1.1 \mathrm{~mL})$ & 0.5 & 0.4 \\
\hline 3 & Mobile phase minus (65:35) & 0.3 & 0.4 \\
\hline 4 & Mobile phase plus $(75: 25)$ & 0.5 & 0.4 \\
\hline 5 & Temperature minus $\left(25^{\circ} \mathrm{C}\right)$ & 0.5 & 0.5 \\
\hline 6 & Temperature plus $\left(30^{\circ} \mathrm{C}\right)$ & 0.9 & 0.7 \\
\hline
\end{tabular}

Table 7: Robustness Results.

\section{Conclusion}

Thus the proposed stability indicating RP-HPLC method for the simultaneous determination of Moexipril and Hydrochlorothiazide in tablet dosage form was accurate, precise, linear, reliable, simple, economic and robust. The method has several advantages, including simple mobile phase, rapid analysis, simple sample preparation and improved selectivity as well as sensitivity. The method can be used for routine analysis of marketed products of Moexipril and Hydrochlorothiazide in combined tablet formulation.

\section{References}

1. Chrysant SG (2004) Pharmacological and clinical profile of Moexipril: a concise review. J Clin Pharmacol 44(8): 827-836.

2. Indian Pharmacopoeia (2014), Volume II, The Indian Pharmacopoeia Commission, Ghaziabad, India. pp: 2305.

3. Savaj BV, Raj HA, Rajanit S, and Harshita S (2015) Analytical techniques for determination of 


\section{Open Access Journal of Pharmaceutical Research}

Hydrochlorothiazide and its combinations: a Review. IJASR 1(3): 114-128.

4. Stanisz B, Regulska K, Ratajczak T (2012) First order Derivative Spectrophotometric and HPLC methods for determination of Moexipril Hydrochloride in the pure form, pharmeceutical formulations and evaluation of its stability. Acta Pol Pharm 69(3): 389-395.

5. Bhagwate S, Gaikwad NJ (2013) Stability indicating HPLC method for the determination of Hydrochlorothiazide in pharmaceutical dosage form. JAPS 3(2): 88-92.

6. Mohammed NS, Mohammad AJ (2016) Development and validation of RP-HPLC method for the determination of Hydrochlorothiazide in bulk drug and pharmaceutical dosage form. Chromatography Research International 2(3): 152-156.

7. Mastiholimath VS, Gupte PP, Mannur VS, Dandagi PM, Gadad AP (2012) Development and validation of a UV Spectrophotometric and a RP-HPLC methods for Moexipril Hydrochloride in pure form and pharmaceutical dosage form. MJAS 16(3): 202-212.

8. Sahoo S, Panda PK, Mishra SK, Sabuj S (2012) HPLC method development for simultaneous estimation of Hydrochlorothiazide and Perindropril in tablet dosage form. Asian J Pharm Clin Res 5(S2): 136-138.

9. Nagavi JB, Anantharaju PG (2017) Analytical RP-HPLC method development and validation for the simultaneous estimation of Ramipril and Hydrochlorothiazide in tablet dosage form. AJPTR 7(3): 349-364.
10. Wankhede SB, Raka KC, Wadkar SB, Chitlange SS (2010) Spectrophotometric and HPLC methods for simultaneous estimation of Amlodipine Besilate, Losartan Potassium and Hydrochlorothiazide in Tablets. Indian J Pharm Sci 72(1): 136-140.

11. Rane VP, Patil KR, Sangshetti JN, Yeole RD, Shinde DB (2010) Stability indicating LC method for simultaneous determination of Irbesartan and Hydrochlorothiazide in pharmaceutical preparation. Journal of Chromatography Sciences 48(7): 595-600.

12. Bankey S, Tapadiya GG, Saboo SS, Bindaiya S, Deepti J, et al. (2009) Simultaneous determination of Ramipril, Hydrochlorothizide and Telmisartan by Spectrophotometry. Int J Chem Tech Res 1(2): 183188.

13. Erturks, Cetin SM, Atmacas S (2003) Simultaneous determination of Moexipril Hydrochloride and Hydrochlorothiazide in tablets by Derivative Spectrophotometric and High-Performance Liquid Chromatographic Methods. J Pharm Biomed Anal 33(3): 505-511.

14. Raju VB, Rao AL (2012) Simultaneous estimation of Moexipril and Hydrochlorothiazide in tablet dosage form by RP-HPLC method. Asian J Chem 24(11): 5026-5028.

15. ICH Harmonised Tripartite Guideline (2005) Validation of Analytical Procedures: Text and Methodology. ICH, Geneva Q2 (R1): 1-13. 